\title{
Speech Pathology
}

National Cancer Institute

\section{Source}

National Cancer Institute. Speech Pathology. NCI Thesaurus. Code C17400.

A field of study concerned with the diagnosis and treatment of disorders of speech and voice. 